\title{
LETTER TO THE EDITOR Identification of increased genetic risk scores for schizophrenia in treatment-resistant patients
}

Molecular Psychiatry (2015) 20, 150-151; doi:10.1038/mp.2014.56; published online 3 June 2014

Schizophrenia is a severe neuropsychiatric disorder that affects around $0.5-1 \%$ of the population. Research has shown that early intervention increases the likelihood of remission and reduces the severity of symptoms, as well as attenuates the decline in social and overall functioning.

Around $30 \%$ of patients fail to respond adequately to the usual antipsychotic medications, and are classified as being treatment resistant. These patients can be treated with the atypical antipsychotic clozapine, ${ }^{2}$ the only evidence-based pharmacotherapy for treatment-resistant schizophrenia. ${ }^{3}$ However, clozapine is associated with severe adverse events and is thus only prescribed in patients who have failed to respond to trials of two other antipsychotics. ${ }^{4}$ This process may take many years. ${ }^{5}$ Since an extended duration of untreated psychosis and lack of efficacy for the initial treatment are however associated with a poorer prognosis, ${ }^{6}$ identification of patients who will eventually require clozapine is an important goal for improving clinical outcome. Research to identify clinical predictors of response prior to treatment initiation has shown that premorbid social functioning (PSF) is among the most reliable measures (for a review see Schennach et al. ${ }^{6}$ ). Furthermore, reports of an association between a family history of psychosis and an unfavourable treatment response ${ }^{7}$ suggest the influence of genetic factors. However, few candidate gene studies have been conducted and their results are inconsistent. ${ }^{8}$

The present study investigated whether a higher genetic risk for schizophrenia is associated with treatment outcome. Genetic risk was assessed by measuring the polygenic risk score, based on the aggregated number of risk loci previously identified from genome-wide association studies in schizophrenia patients ${ }^{9}$ with

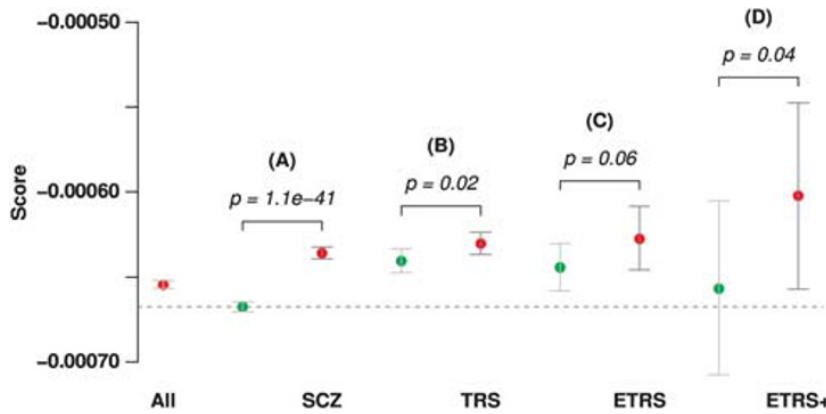

Figure 1. Comparison of polygenetic risk scores between: (A) population-based controls vs all schizophrenia patients (SCZ) (B) patients responding to standard medication vs patients with treatment-resistant schizophrenia (TRS) requiring clozapine treatment; (C) patients responding to clozapine vs patients with extreme treatment-resistant schizophrenia (ETRS) not even responding to clozapine; (D) patients with ETRS only vs patients with ETRS and additional poor premorbid social adjustment and early and insidious disease onset (ETRS+; $P$-values derived from right-tailed logistic regression models). a history of clozapine treatment $\left(\mathrm{Cloz}^{+}, n=434\right)$ compared to patients with no history of clozapine treatment $\left(\mathrm{Cloz}^{-}, n=370\right)$. Furthermore, the $\mathrm{Cloz}^{+}$and $\mathrm{Cloz}^{-}$groups were compared in terms of selected premorbid clinical features (that is, age and mode of onset; poor premorbid work and social adjustment; premorbid personality disorder; alcohol and drug abuse; family history of schizophrenia and other psychiatric disorder; psychosocial stressors; see Supplementary Information).

The polygenic risk score was increased in $\mathrm{Cloz}^{+}$compared to $\mathrm{Cloz}^{-}$patients $(P=0.02)$. Furthermore, polygenic risk scores were higher in $\mathrm{Cloz}^{+}$responders compared to $\mathrm{Cloz}^{+}$non-responders $(P=0.06)$.

Poor PSF was significantly more frequent in $\mathrm{Cloz}^{+}$patients $\left(P=8.1 \times 10^{-5}\right.$; odds ratio $(\mathrm{OR})=1.85$; confidence interval $(\mathrm{Cl})=[1.35-2.55]) . \mathrm{Cloz}^{+}$patients also displayed a significantly earlier age-at-onset $(\bar{x}=23.0 ;$ s.d. $=8.26)$ than $\mathrm{Cloz}^{-}$patients $\left(\bar{x}=25.5\right.$, s.d. $\left.=9.12 ; P=3.0 \times 10^{-6}\right)$, and a higher frequency of insidious disease onset $\left(P=4.4 \times 10^{-3}\right)$. A correlation was observed between poor PSF, early age-at-onset and insidious disease onset. However, this was modest and did not exceed $23 \%$ (for details see Supplementary Information). The highest polygenic risk scores were observed in $\mathrm{Cloz}^{+}$non-responders with poor PSF and an insidious and early disease onset $(P=0.04$; see Figure 1$)$. These clinical variables correlated with both treatment resistance and polygenic score, and when included in the regression model they diminished the influence of polygenic score to nonsignificant values, whereas the associations with TRS per se, as corrected for polygenic score, remained significant.

The finding that poor PSF, an insidious disease onset and an early age-at-onset were associated with poor treatment response is consistent with previous data. ${ }^{10}$ However, the present study is the first to provide molecular evidence that an increased genetic loading for schizophrenia is a further risk factor. However, full interpretation of the results may depend on the proportion of treatment-resistant individuals in the discovery sample (for further discussion see Supplementary Information).

The absence of a positive family history of schizophrenia from the list of associated outcome features may have been attributable to the limited sample size. However, a post hoc analysis showed that a positive family history of schizophrenia was significantly associated with increased schizophrenia risk score in the overall sample (see Supplementary Table 4).

Our findings may suggest the existence of a more severe, genetically based schizophrenia subgroup, for whom early intervention with clozapine could be considered. This may have important implications for clinical practice, and further research is therefore warranted.

\section{CONFLICT OF INTEREST}

David A Collier is a full time employee of Eli Lilly and Company Ltd. The other authors have no conflicts of interest or possible conflicts of interest to declare.

\section{ACKNOWLEDGMENTS}

This study was supported by the German Federal Ministry of Education and Research (BMBF) through the Integrated Genome Research Network (IG) MooDS (Systematic 
Investigation of the Molecular Causes of Major Mood Disorders and Schizophrenia; grant 01GS08144 to Markus M Nöthen and Sven Cichon, grant $01 G 508147$ to Marcella Rietschel), under the auspices of the National Genome Research Network plus (NGFNplus), and through the Integrated Network IntegraMent (Integrated Understanding of Causes and Mechanisms in Mental Disorders, grant BMBF01ZX1314G), under the auspices of the e:Med Programme. Markus M Nöthen is a member of the DFG-funded Excellence Cluster ImmunoSensation. The research that led to these results received funding from the European Community's Seventh Framework Programme (FP7/2007-2013) under grant agreement no. 279227 (CRESTAR). Further funding was provided by the European Union Seventh Framework Programme (FP7/2007-2011) under grant agreement no. 242257 (ADAMS).

J Frank ${ }^{1}$, M Lang ${ }^{1}$, SH Witt ${ }^{1}$, J Strohmaier ${ }^{1}$, D Rujescu ${ }^{2}$, S Cichon ${ }^{3,4,5}$, F Degenhardt ${ }^{4}$, MM Nöthen ${ }^{4}$, DA Collier $^{6,7}$, S Ripke $^{8}$, D Naber ${ }^{9}$ and $M$ Rietschel ${ }^{1}$

${ }^{1}$ Department of Genetic Epidemiology in Psychiatry, Central Institute of Mental Health, Clinical Faculty Mannheim, Heidelberg University, Mannheim, Germany; ${ }^{2}$ University Hospital and Outpatient Hospital for Psychiatry, Psychotherapy and Psychosomatic Medicine, Martin-Luther-University Halle-Wittenberg, Halle, Germany; ${ }^{3}$ Division of Medical Genetics, University Hospital Basel, Department of Biomedicine, University of Basel, Basel, Switzerland;

${ }^{4}$ Life \& Brain Center for Genomics, Institute of Human Genetics, University of Bonn, Bonn, Germany;

${ }^{5}$ Institute of Neuroscience and Medicine (INM-1), Structural and Functional Organization of the Brain, Genomic Imaging, Research Center Juelich, Juelich, Germany;

${ }^{6}$ Institute of Psychiatry, King's College London, London, UK; ${ }^{7}$ Eli Lilly and Company Limited, Erl Wood Manor, Windlesham, Surrey, UK;

${ }^{8}$ Analytic and Translational Genetics Unit, MGH Simches Research Center, Boston, MA, USA and
${ }^{9}$ Center for Psychosocial Medicine, Department of Psychiatry and Psychotherapy, University Hospital Hamburg-Eppendorf, Hamburg,

Germany

E-mail: marcella.rietschel@zi-mannheim.de

\section{REFERENCES}

1 Marshall M, Lewis S, Lockwood A, Drake R, Jones P, Croudace T. Arch Gen Psychiatry 2005; 62: 975-983.

2 Leucht S, Cipriani A, Spineli L, Mavridis D, Orey D, Richter F et al. Lancet 2013; 382: 951-962.

3 Essali A, Al-Haj Haasan N, Li C, Rathbone J. In: The Cochrane Collaboration, Essali A (eds). Cochrane Database Syst Rev [Internet]. John Wiley \& Sons, Ltd: Chichester, UK, 2009. Available from: http://doi.wiley.com/10.1002/14651858.CD000059.pub2 (cited 1 August 2013).

4 Nielsen J, Nielsen RE, Correll CU. J Clin Psychopharmacol 2012; 32: 678-683.

5 Taylor DM, Young C, Paton C. J Clin Psychiatry 2003; 64: 30-34.

6 Schennach R, Riedel M, Musil R, Möller H-J. Clin Psychopharmacol Neurosci 2012; 10: 78.

7 Crespo-Facorro B, de la Foz VO-G, Ayesa-Arriola R, Pérez-Iglesias R, Mata I, SuarezPinilla P et al. Prog Neuropsychopharmacol Biol Psychiatry. 2013; 44: 162-167.

8 Zhang J-P, Malhotra AK. Expert Opin Drug Metab Toxicol 2011; 7: 9-37.

9 Ripke S, Sanders AR, Kendler KS, Levinson DF, Sklar P, Holmans PA et al. Nat Genet 2011; 43: 969-976.

10 Kelly DL, Feldman S, Boggs DL, Gale E, Conley RR. Compr Psychiatry 2010; 51: 298-302.

(c) This work is licensed under a Creative Commons AttributionNonCommercial-ShareAlike 3.0 Unported License. The images or other third party material in this article are included in the article's Creative Commons license, unless indicated otherwise in the credit line; if the material is not included under the Creative Commons license, users will need to obtain permission from the license holder to reproduce the material. To view a copy of this license, visit http:// creativecommons.org/licenses/by-nc-sa/3.0/

Supplementary Information accompanies the paper on the Molecular Psychiatry website (http://www.nature.com/mp) 